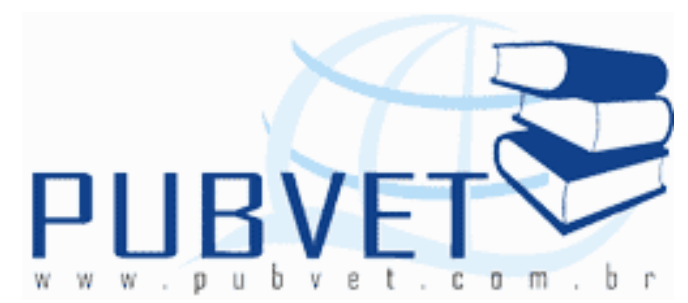

PUBVET, Publicações em Medicina Veterinária e Zootecnia.

DOI: https://doi.org/10.31533/pubvet.v01n06a66.1-32

\title{
Resíduos agroindustriais na alimentação de ruminantes: uma revisão
}

\section{Daniele Maggioni ${ }^{1}$ e Jair de Araújo Marques ${ }^{2}$}

${ }^{1}$ Doutoranda do Programa de Pós-Graduação em Zootecnia - UEM e Professora da Faculdades Integrado de Campo Mourão

2Doutor em Zootecnia, Professor Adjunto da Universidade Federal do Recôncavo da Bahia, UFRB e Pesquisador Visitante da Universidade Estadual do Sudoeste da Bahia, UESB

\section{INTRODUÇÃO}

A entressafra de produção de forragem provocada por peculiaridades climáticas (estacionalidade devido a concentração de ocorrências de chuvas) constitui para os produtores, um período do ano cheio de dificuldades para que se possa fornecer ao seu rebanho uma alimentação equilibrada do ponto de vista nutricional.

Além disso, as atividades agrícolas e pecuárias apresentam ciclos econômicos. Atualmente a agricultura apresenta lucros muito atraentes, sobretudo a soja, o que vem acarretando alta do preço de insumos e elevação do preço do arrendamento de pastos. O que torna esta fase pouco favorável aos 
pecuaristas, pois o preço da arroba de boi não vem acompanhando a elevação destes custos, e além disto a pecuária ainda têm de enfrentar a concorrência com a oleaginosa em áreas que até pouco tempo eram redutos absolutos da criação de gado. Calcula-se que nos próximos 15 anos, cerca de 30 milhões de hectares, hoje usados com pastagem, serão transformados em terras agrícolas.

Uma alternativa que vem ganhando espaço entre os pecuaristas como forma de driblar os altos custos da atividade e a entressafra de produção de forragem é a intensificação da criação de gado, ou seja, a adoção de técnicas de manejo que prevêem a criação de maior número de animais na mesma área ou mesmo número de animais em área menor. Alguns estudos revelam que em propriedades em que a produção caracteriza-se pela baixa lotação, a introdução de um manejo rotacionado eficiente pode elevar a produtividade em até $90 \%$, e se, juntamente com essa técnica, o produtor adotar o confinamento, o ganho produtivo poderá chegar a 600\% (Figueiró, 2004).

O confinamento de bovinos de corte é uma estratégia para terminação cuja flexibilidade advém da variação de parâmetros zootécnicos, bem como dos econômicos de cada região onde a pecuária se insere. $O$ custo da alimentação é um dos fatores mais limitantes para o confinamento de bovinos de corte. A produção intensiva de bovinos de corte representa uma dificuldade à produção de carne nacional, em função do alto custo de alimentação. Isto ocorre devido o uso de alimentos usados na dieta de humanos e de monogástricos.

Com a necessidade de intensificação dos sistemas de produção de carne bovina no Brasil, pesquisadores e técnicos estão buscando alternativas, que possibilitem melhores combinações de alimentos concentrados, (Monteiro et al. 1998). Assim existe a necessidade de utilização de alimentos alternativos, objetivando minimizar os custos de produção e maximizar a produção de carne, assim como a qualidade da mesma. Surge, então, a possibilidade de 
uso de resíduos agroindustriais que apresentem características nutritivas favoráveis à alimentação de ruminantes.

Vários subprodutos são passíveis de serem utilizados na alimentação de ruminantes, haja visto, que o ruminante apresenta um sistema digestivo peculiar, capaz de converter, em alimentos de alta qualidade, produtos fibrosos de plantas e subprodutos diversos. Entretanto, muitos subprodutos são sub utilizados, em função do desconhecimento de suas potencialidades, valor nutritivo e deficiências que devem ser corrigidos para um melhor desempenho animal.

O Brasil possui enorme quantidade de resíduos e subprodutos da agricultura e da agroindústria, com potencial de uso na alimentação de ruminantes, (Prado \& Moreira, 2002).

Este trabalho tem o objetivo de descrever as características de alguns resíduos que estão sendo utilizados atualmente, assim como suas potencialidades, deficiências e resultados na alimentação de bovinos.

\section{Resíduos Industriais de Abacaxi}

O Brasil ocupa lugar de destaque na produção mundial de abacaxi. No ano de 2003 a sua produção cresceu cerca de 80\%, passando a produzir aproximadamente 2,5 milhões de toneladas. Com o aumento do número de agroindústrias para o beneficiamento de abacaxi, grande quantidade de subprodutos, resultantes do processamento de frutos, é gerada anualmente. Durante a industrialização do abacaxi sobram nas fábricas cascas, talos, coroas e cilindros, considerados rejeitos, que em média chegam $30 \%$ a $40 \%$ do peso da matéria-prima processada.

No entanto, muitas vezes, por falta de informações, os resíduos do abacaxi acabam sendo inutilizados, desperdiçando um subproduto com possibilidade de 
utilização na alimentação de ruminantes, além de contribuir para redução da poluição ambiental.

O uso de resíduos industriais de abacaxi na alimentação de bovinos foi estudado por Rodrigues \& Peixoto (1990b) e estes observaram que o resíduo possui características nutricionais que possibilita sua utilização para bovinos, podendo ser considerada como uma boa fonte de volumoso. Enquanto, Muller (1978), constatou que o valor nutritivo apresentado pelos resíduos do abacaxi deve-se a concentração de carboidratos solúveis, representando dessa forma fonte alternativa de energia para os ruminantes.

Uma das formas de uso dos resíduos do abacaxi é a silagem. A silagem de resíduos industriais de abacaxi é constituída de casca, coroa e miolo, entre estes estão presentes também frutos inteiros descartados, apresentando assim pequena quantidade de polpa. Este resíduo pode ser obtido na indústria produtora de fatias de abacaxi em calda sem miolo.

Prado et al. (2003), observaram que a silagem de resíduos industriais de abacaxi apresentou composição química e características fermentativas (cor, odor e $\mathrm{pH}$ ) favoráveis, podendo ser utilizada como alimento alternativo para terminação de bovinos de corte, em confinamento.

A silagem de resíduos industriais de abacaxi apresenta características nutricionais próximas à da silagem de milho, por isto pode ser uma potencial substituta como fonte de volumoso para animais em confinamento. Além da qualidade nutricional, é um produto de baixo custo por ser considerado um resíduo, diferente de outros freqüentemente utilizados, como por exemplo, a silagem de milho, que apresenta altos valores no período de entressafra do milho. Dessa maneira, o produtor passaria a dispor de mais uma alternativa de volumoso, seja durante o período de escassez de forragem, ou como alimento para o confinamento. 
A composição química da silagem de resíduos industriais de abacaxi (Tabela 1), varia em função do tipo de resíduo gerado, ou seja, de acordo com o produto da indústria, compondo assim, o resíduo de diferentes partes da planta ou do fruto. Rodrigues \& Peixoto (1990b) utilizaram frutos descartados sem coroa, casca e miolo, como resíduo ensilado, e obtiveram valores de $12,93 \%$ de MS; $3,95 \%$ de PB; $62,76 \%$ de FDN e $41,24 \%$ de FDA. Em outro trabalho Rodrigues \& Peixoto (1990a), utilizando outro tipo de resíduo, não ensilado, composto de frutos descartados, casca, miolo e coroa, obtiveram valores de $14,82 \%$ de MS; $5,47 \%$ de PB; $62,26 \%$ de FDN e $25,58 \%$ de FDA. Estes dados demonstram a variação da composição química deste resíduo, conforme o meio de sua obtenção, processamento e utilização.

Em função da sua composição química, a silagem de resíduos industriais de abacaxi pode ser considerada um alimento volumoso de considerável teor protéico, pois sua composição em proteína bruta (PB) é superior a da silagem de milho $(6,50$ a $7,05 \%)$. A silagem de resíduos industriais de abacaxi pode apresentar teores de PB semelhantes aos teores de PB do bagaço de laranja ensilado (Ítavo et al. 2000), da polpa de citrus (Pinheiro et al., 2000 e Branco et al., 1994), do resíduo de maracujá (Siqueira et al., 1999). No entanto, o teor de proteína deste resíduo pode ser variável em função do material coletado e período de utilização, como os observados por Rodrigues \& Peixoto (1990b), estes autores encontraram menor teor de PB (3,9\%) para um resíduo de abacaxi ensilado (sem coroa). Este produto pode apresentar deficiência em energia e proteína ou ambos, exigindo o fornecimento de uma fonte de suplementação adequada.

Prado et al. (2003) realizaram trabalho para avaliar a substituição gradativa da silagem de milho $(0,20,40$ e $60 \%$, em base na matéria seca) pela silagem de resíduos industriais de abacaxi sobre o ganho médio diário, ingestão de alimentos e conversão alimentar, rendimento de carcaça, gordura de cobertura 
e área de olho de lombo de bovinos terminados em confinamento e constataram que não houve alteração do desempenho animal, da conversão alimentar e do rendimento de carcaça. Estes autores então sugerem a utilização da silagem de resíduos industriais de abacaxi na terminação de bovinos de corte.

Lallo et al. (2003), trabalhando com níveis de substituição da silagem de milho pela silagem de resíduos industriais de abacaxi observaram uma pequena alteração na dinâmica da fermentação ruminal, dessa forma estes autores indicam que a silagem de resíduos industriais de abacaxi pode substituir a silagem de milho em até $60 \%$ (base da MS) nas rações para bovinos em confinamento, sem afetar a fermentação ruminal. Outro trabalho deste mesmo grupo de pesquisadores demonstra que a substituição da silagem de milho pela silagem de resíduo industrial de abacaxi, proporciona uma redução linear na digestibilidade aparente da matéria seca, matéria orgânica, proteína bruta e energia bruta, (Lallo et al., 2002).

Outra forma de uso dos resíduos do abacaxi é o subproduto do suco. Ferreira et al. (2004), observaram que a adição de níveis de subproduto da indústria do suco de abacaxi na silagem de capim elefante proporcionou aumento linear nos teores de MS nas silagens. Com a adição de $14 \%$ do resíduo de abacaxi, a silagem atingiu um teor médio de $27,20 \%$ de MS, valor muito próximo, portanto da faixa de $28-34 \%$ de MS tido como ideal por McCullough (1977), para que haja um eficiente processo fermentativo da silagem. Estes autores também observaram um acréscimo nos teores de PB com a adição de subprodutos de abacaxi nas silagens de capim elefante. Em relação aos teores de FDN e FDA observaram uma redução linear nos seus níveis com a adição do subproduto de abacaxi à silagem de capim. Fato que já era esperado, pois os níveis de FDN e FDA do capim elefante puro $(73,9 \%$ e $38,8 \%)$ eram superiores ao FDN e FDA do resíduo do abacaxi $(60,7 \%$ e $24,1 \%)$ adicionado à silagem. A 
adição deste subproduto manteve o pH e o teor de amônia da silagem dentro dos níveis característicos de silagens bem preservadas.

Todos estes dados reforçam a idéia que subprodutos da indústria do abacaxi podem ser usados na alimentação animal, principalmente pelo fato de contribuírem para minimizar os custos de produção. Porém, é importante ressaltar que a silagem oriunda de frutos contém alta porcentagem de água, que acaba dificultando o transporte dos mesmos, devendo a propriedade localizar-se próxima a indústria geradora de resíduos.

TABELA 1: Composição Química da Silagem de Resíduos Industriais de Abacaxi e de Subprodutos do Suco de Abacaxi.

\begin{tabular}{|c|c|c|c|c|c|}
\hline Resíduo & $\begin{array}{l}\text { MS } \\
(\%)\end{array}$ & MO $^{a}$ & PB $^{\mathbf{a}}$ & FDN $^{a}$ & $\mathrm{MM}^{a}$ \\
\hline $\begin{array}{llll}\text { Silagem de } & \text { Res. Ind. } \\
\text { Abacaxi } & & & \end{array}$ & 14,78 & 82,98 & 8,83 & 64,70 & 17,02 \\
\hline $\begin{array}{l}\text { Subproduto do Suco } \\
\text { Abacaxi }\end{array}$ & 87,40 & - & 9,28 & 60,74 & 24,12 \\
\hline
\end{tabular}

a Valores expressos como \% da matéria seca.

Adaptado de Prado et al. (2003); Ferreira et al. (2004).

\section{Resíduos Industriais de Citrus}

Com mais de um milhão de hectares de plantas cítricas em seu território, o Brasil tornou-se, na década de 80, o maior produtor mundial de laranjas, posição esta que ocupa até os dias de hoje (ABECITRUS 2003). A maior parte da produção brasileira de laranjas destina-se à indústria do suco, concentrada no estado de São Paulo e responsável por $70 \%$ das laranjas e $98 \%$ do suco 
que o Brasil produz. Segundo dados da FAO (2000), na safra de 98/99 o Brasil foi responsável por aproximadamente $30 \%$ da produção mundial de laranja.

A indústria de suco de laranja produz como subproduto o bagaço, que compreende $42 \%$ do total da fruta.

Procurando minimizar custos para ruminantes, pesquisadores optaram pela utilização da polpa cítrica, ou como também é chamado, bagaço de laranja, que pode ser utilizado na alimentação de bovinos como alimento energético, em substituição ao milho na entressafra. Nas regiões de grande disponibilidade de citrus, o aproveitamento da polpa como resíduo da produção de sucos pode ser uma alternativa para se contornar a qualidade e redução da oferta de forragens e grãos de cereais. Alguns países como os Estados Unidos usam até $90 \%$ de sua produção de polpa cítrica na alimentação de vacas leiteiras, (Moreira et al., 2004).

A polpa cítrica desidratada ou seca é um subproduto composto pelos resíduos (cascas, sementes e polpa) obtidos durante a extração do suco de laranja e limão. O processamento para obtenção da polpa cítrica peletizada (PCP), é realizado através de prensagens e secagem do material "in natura", elevando sua matéria seca, para $90 \%$. Na etapa de secagem são usados tambores a óleo ou a vapor podendo ocorrer problemas de excesso de temperatura, causando carbonização da PCP, que passa a apresentar uma cor escura e qualidade nutricional reduzida.

A polpa cítrica pode representar uma alternativa de interesse, devido as suas características nutricionais (concentração energética elevada, equivalente à do milho, alta digestibilidade e palatabilidade), da alta disponibilidade e baixo preço de mercado. Além de a polpa cítrica apresentar ótima qualidade nutricional, (Tabela 2), para alimentação de ruminantes, sua época de maior disponibilidade é extremamente favorável, pois coincide com a entressafra do milho. Segundo Van Soest (1994), a polpa cítrica é considerada um 
concentrado energético e em função do alto teor de fibra e pectina, a polpa cítrica é rapidamente degradada no rúmen, liberando energia para um acelerado crescimento microbiano. A polpa cítrica apresenta também reduzido teor de lignina o que possibilita ampla digestão da celulose e da hemicelulose. Estas características tornam a polpa cítrica um alimento muito utilizado em dietas de animais de alta exigência energética. Porém, sua principal limitação nutricional é seu baixo teor protéico. Henrique et al. (1998) não verificaram problemas com a utilização de níveis elevados de polpa na dieta de novilhas, seja em nível de ingestão, seja de desempenho e Monteiro et al. (1998) citam a possibilidade de substituição de até $45 \%$ do milho da dieta pela polpa cítrica, sem alteração no desempenho nem nas características de carcaça de cordeiros confinados.

Tradicionalmente, os concentrados empregados na alimentação animal caracterizam-se por possuir amido como principal componente energético (Orskov, 1987). Alimentos com alto teor de amido favorecem a produção de ácido propiônico no rúmen e induz o animal à acidose com maior facilidade do que alimentos que promovem a fermentação acética. Ítavo et al. (1999), observaram que, de acordo com o padrão de produção de ácidos graxos voláteis em sua fermentação, a polpa cítrica apresenta tendência em manter o $\mathrm{pH}$ ruminal em patamares mais elevados e em aumentar a produção de ácido acético em comparação aos alimentos energéticos tradicionais.

Bruno Filho et al. (2000), observaram que a inclusão de PCP em dietas aumenta os coeficientes de digestibilidade dos nutrientes, demonstrando que a PCP aumenta a densidade energética da ração, podendo ocasionar ganhos em produtividade, exceto para a proteína bruta (PB), pois quando se aumenta o nível de PCP na dieta, o coeficiente de digestibilidade deste nutriente foi reduzido, o que pode ser explicado devido ao alto teor de nitrogênio retido na parte fibrosa (N-FDA). 
Henrique et al. (1998), avaliaram dois níveis de concentrados (20 e 80\%) e dois alimentos energéticos (milho e polpa cítrica) e observaram que, nos tratamentos com $20 \%$ de concentrado, a substituição do milho pela polpa não influenciou o ganho médio diário e o consumo. Entretanto, nos tratamentos em que o concentrado participou com $80 \%$ da matéria seca total da dieta, essa substituição resultou em diminuição considerável do consumo de matéria seca e, conseqüentemente do ganho de peso. Estes autores atribuem o baixo consumo ao excesso de cálcio presente na polpa cítrica, que poderia ter reduzido a digestibilidade da proteína bruta e da energia, bem como ter afetado o metabolismo do fósforo, magnésio e outros minerais traços. Diminuição do consumo também foi encontrada por Faturi et al. (2004), que observaram que os animais tendem a selecionar o alimento volumoso, e apresentam consumo abaixo do esperado quando alimentados com dietas compostas por alta proporção de polpa cítrica.

Fontes et al. (2004), avaliando o efeito de duas fontes energéticas (milho e polpa cítrica) associadas a duas fontes protéicas (farelo de girassol e uréia) sobre o desempenho de novilhos confinados, observaram que a utilização da polpa cítrica em substituição ao milho, associadas ao farelo de girassol, não afeta o desempenho de novilhos confinados, entretanto, a utilização da polpa cítrica associada à uréia na dieta pode provocar diminuição do consumo e, conseqüentemente, do ganho de peso.

Velloso (1985) utilizou a polpa cítrica em substituição ao milho na dieta para novilhos confinados, recomendando nível de até $30 \%$, sem piorar a conversão alimentar e sem alteração das características das carcaças.

No entanto o custo de secagem/desidratação da polpa úmida é elevado (Carvalho, 1995), e o bagaço tem seu valor nutritivo rapidamente reduzido durante a estocagem, às vezes em até 50\% (Ashbell \& Weinberg, 1988). Tais razões acentuam a necessidade de estudos de forma e métodos para 
conservação do valor nutricional desse subproduto. Com o intuito de reduzir os custos Ashbell (1992), sugeriu uma nova alternativa para o uso da polpa cítrica, que é a técnica de ensilagem do resíduo.

A silagem de bagaço de laranja pode substituir a silagem de milho, diminuindo os custos de produção em regiões onde está disponível, é o que concluem Ítavo et al. (1999). Estes pesquisadores não observaram alterações significativas para os parâmetros ruminais e o consumo, portanto a silagem de bagaço de laranja é perfeitamente aceita, sem alterações nas funções de produção dos ruminantes. Observaram também que o $\mathrm{pH}, \mathrm{ON}$ amoniacal e os ácidos graxos voláteis produzidos permaneceram dentro da normalidade, sem indício de qualquer alteração prejudicial ao ambiente ruminal.

Para possibilitar a ensilagem da polpa cítrica Bergamaschine et al. (1998), utilizaram a adição de rolão de milho, ou cama de frango e uréia, ou suas associações e observaram que estes materiais são bons aditivos para ensilagem de polpa úmida de citrus. Surita et al. (1998), observaram que o uso de aditivos como uréia, farelo de algodão, farelo de soja e grão de soja na silagem de bagaço de laranja, não afetam negativamente o $\mathrm{pH}$ e a capacidade tamponante do bagaço e que o uso de aditivos protéicos com alto teor de MS elevaram os teores de MS e PB, sem afetar o conteúdo de parede celular das silagens. Estes autores concluem que o uso de tais aditivos constitui uma boa alternativa para produção de silagens de bagaço de laranja. 
TABELA 2. Composição Química do Bagaço de Laranja.

\begin{tabular}{l|ccccc}
\hline Resíduo & NDT $^{\mathbf{a}}$ & PB $^{\mathbf{a}}$ & FDNa $^{\mathbf{a}}$ & FDA $^{\mathbf{a}}$ & Lignina $^{\mathbf{a}}$ \\
\hline Bagaço de & $83,0-88,0$ & 7,0 & $23,0-$ & 17,02 & $1,0-3,0$ \\
Laranja & & & 25,0 & & \\
\hline
\end{tabular}

a Valores expressos como \% da matéria seca.

Adaptado de Van Soest (1994) e Ítavo et al. (1999).

\section{Resíduos Industriais de Algodão}

A casca de algodão é um subproduto oriundo da extração da camada externa do caroço do algodão durante a produção de óleo. Este resíduo apresenta alto teor de fibra em detergente neutro $(73,5 \%$ até $89 \%)$, o que a torna pouco atraente para a alimentação de monogástricos, porém pobre em $\mathrm{PB}$, além de apresentar baixa degradabilidade efetiva da matéria seca. A produção em grande quantidade também torna o produto atraente, pois, para cada tonelada de caroço de algodão processado resultam aproximadamente $245 \mathrm{~kg}$ de casca.

Chizzotti et al. (2003), utilizando níveis diferentes de casca de algodão peletizada em substituição à silagem de capim elefante em novilhos relataram que houve aumento linear no consumo de matéria seca e de FDN à medida que aumentou o nível de inclusão da casca de algodão na dieta.

Os baixos coeficientes para digestibilidade in vitro da MS e de FDN (DIVMS e DIVFDN), apresentadas pela casca de algodão podem ser explicados devido aos altos teores de lignina encontrados neste resíduo, o que dificulta a digestibilidade, (Paroliz et al., 2004). O baixo teor de proteína bruta também pode contribuir para a menor DIVMS. Paroliz et al. (2004) analisando a digestibilidade in vitro de alguns resíduos, observaram que a casca de algodão apresenta DIVMS e DIVFDN menores que a casca de soja. 
Apesar da casca de algodão apresentar composição química (Tabela 3) que a caracterize como volumoso de baixa qualidade, Chizzotti et al. (2003), demonstraram que a casca de algodão pode substituir a silagem de capim elefante, sem afetar negativamente o consumo e a digestibilidade da dieta.

Assis et al. (2004), substituindo a silagem de milho pela casca de algodão em dietas de vacas leiteiras, não observaram alteração para a produção de leite pelos níveis crescentes de casca de algodão das dietas. Entretanto, alguns constituintes do leite foram alterados pelo uso deste resíduo, como a gordura do leite que foi afetada linearmente com o acréscimo da casca de algodão na dieta. Estes autores concluem que a casca de algodão pode substituir a silagem de milho em até $21 \%$ da matéria seca total da dieta de vacas leiteiras contribuindo para a melhoria da composição do leite.

Outro resíduo utilizado na alimentação animal e proveniente da indústria algodoeira é o caroço de algodão. Este resíduo é obtido através da separação da fibra na indústria beneficiadora e apresenta em média, $20 \%$ de proteína bruta e $20 \%$ de óleo.

O caroço de algodão integral tem grande potencial de utilização em dietas de ruminantes em função de seus teores elevados de energia, na forma de óleo, proteína e fibra (FDN). Suas fibras são similares às das forragens em termos de digestão no rúmen, mas é possível que a gordura do caroço cause problemas de absorção de nutrientes, pois os ácidos graxos reduzem o pH ruminal, assim como a atividade microbiana ruminal, porém sua fibra pode ser útil no arraçoamento de animais com altas proporções de concentrados na dieta.

A inclusão de gordura nas dietas de ruminantes é usada para diminuir o balanço energético negativo no começo da lactação e melhorar o desempenho 
de novilhos em confinamento. Mas há indícios que este tipo de dieta altera a composição de lipídios da carcaça ou do leite de bovinos, (Assis et al., 2004). Moletta (1999), avaliando o efeito da inclusão do caroço de algodão ou grão de soja para a alimentação de novilhos confinados, não detectou influências sobre as características de carcaça, porém os animais alimentados com caroço de algodão apresentaram uma tendência à maior deposição de gordura nas carcaças. Neste mesmo trabalho, não foi observada diferença na eficiência alimentar $(0,161$ e 0,160 para o grão de soja e caroço de algodão, respectivamente) e no rendimento de carcaça entre os tratamentos.

Segundo Vilella et al. (1995), a inclusão de até 30\% de caroço de algodão em rações concentradas não afeta os consumos de MS, MO, PB, FDN e NDT, bem como também não verificaram influências sobre a eficiência na síntese de proteína microbiana nem sobre os coeficientes de digestibilidade da MS, MO, PB e EE.

TABELA 3. Composição Química da Casca de Algodão.

\begin{tabular}{|c|c|c|c|c|c|}
\hline Resíduo & MS (\%) & $\mathbf{P B}^{\mathbf{a}}$ & Lignina $^{a}$ & FDNa & $\overline{\text { FDA }^{a}}$ \\
\hline Casca & $91,8-$ & $3,8-4,8$ & $8,7-$ & 88,0 & 56,6 \\
\hline Algodão & 93,2 & & 10,4 & & \\
\hline
\end{tabular}

a Valores expressos como \% da matéria seca.

Adaptado de Paroliz et al. (2004).

\section{Resíduos Industriais de Soja}

O Brasil vem ganhando o mercado mundial de soja a cada ano e a expectativa é que, em cinco anos, o país passe a liderar a produção mundial do grão. É alta a velocidade de expansão do plantio desta oleaginosa e a cada passo desenvolvem-se novas plantas, que transformam a soja em grão, em óleo, 
farelo bruto, lecitina, entre outros derivados, e que geram grande quantidade de resíduos. Alguns destes subprodutos da soja podem ser utilizados na alimentação de ruminantes.

O uso de subprodutos energéticos ricos em fibra de alta digestibilidade tem sido pesquisado como alternativa ao uso de grãos ricos em amido. Um destes subprodutos é a casca de soja, ou como também é chamada, casquinha de soja. A casca do grão de soja é o tegumento que é retirado durante o descascamento inicial dos grãos, antes da extração do óleo.

A composição da casquinha de soja (Tabela 4), é bastante variável e depende do processamento usado na obtenção do farelo de soja. Quando se deseja farelo de soja mais rico em PB, mais cascas de soja são retiradas e o contrário também é verdadeiro, farelo de soja com menos teor de PB tem mais casca de soja e maiores teores de FDN e lignina.

A casca de soja tem uma fina película, rica em pectina que confere ao resíduo alta digestibilidade. Durante o processo de secagem dos grãos, esta película pode se desprender da casca, alterando a composição do resíduo. O que leva a concluir que os resíduos não têm uma uniformidade quanto ao seu teor em nutrientes e, portanto, apresentam uma variação considerável, necessitando da caracterização nutricional a cada partida produzida.

A casca de soja apresenta características fibrosas dos volumosos ao mesmo tempo em que disponibiliza energia semelhante aos alimentos concentrados. Apesar do elevado teor de fibra, a digestibilidade da FDN pode alcançar $95 \%$.

O milho (grãos), apesar de seu elevado valor energético, quando usado em dietas mistas de volumosos e concentrados, pode provocar uma redução da digestibilidade da fração fibrosa da dieta (Grigsby et al., 1993 e Chase \& Hibberd, 1987). Os resultados de diversos trabalhos indicam que a casca de 
soja parece provocar um menor efeito negativo sobre a digestão da fibra, em relação aos alimentos ricos em amido, proporcionando um desempenho semelhante ao desses alimentos (Anderson et al., 1988).

Thiago et al. (2000), constataram que a casca de soja pode substituir satisfatoriamente o grão de milho, em rações para a engorda de animais confinados. Neste trabalho a casca de soja substituiu com vantagens o grão de milho, em termos de ganho de peso e não afetou as características de carcaças. A ausência do efeito desta substituição sob o desempenho animal, associado com o menor custo da casca de soja perante o grão de milho, propiciam vantagens no custo da arroba ganha durante o confinamento. Gomes \& Andrade (1996) trabalhando com níveis de substituição do milho pela casquinha de soja, em dietas contendo de 30 a 70\% de concentrados, também não encontraram diferenças no ganho de peso e na conversão alimentar de garrotes confinados. Este mesmo grupo de pesquisadores, concluíram que a casca de soja pode substituir totalmente o milho (grãos) sem afetar a digestibilidade da MS, MO, EB e os valores de NDT de dietas contendo de 30 a $70 \%$ de alimentos concentrados (Gomes \& Andrade, 1998).

Gastaldi et al. (2000), avaliando o desempenho de novilhos Nelore confinados, alimentados com duas fontes de nitrogênio, duas relações volumoso:concentrado e substituição ou não de $30 \%$ do volumoso por casca de soja, constataram que a adição de casca de soja às dietas, proporcionou menor consumo de matéria seca pelos animais, entretanto, verificaram que os ganhos de peso total e diário destes foram superiores. Provavelmente, este maior ganho de peso foi devido a maior concentração de energia proporcionada pela substituição parcial do feno pela casca de soja, reconhecidamente bem aproveitada no rúmen.

Outro produto oriundo da soja é o farelo. O farelo de soja (Tabela 4), apresenta elevado teor protéico (se o grão for descascado antes da extração 
do óleo). Através da extração do óleo dos grãos de soja se obtem a torta de soja, que após a sua tostagem e moagem origina o farelo de soja. A torta em si é o que permanece após a extração do óleo com solventes.

O farelo de soja constitui uma importante fonte de proteína em dietas, contudo, as recentes flutuações da moeda americana refletiram num aumento considerável do custo desse ingrediente, praticamente inviabilizando a sua inclusão.

De acordo com NRC (1996) machos não castrados e em fase de crescimento necessitam de inclusão de uma fonte suplementar de proteína verdadeira, como o farelo de soja, em substituição parcial ou total a uréia, com o objetivo de suprir as exigências em proteína metabolizável. Estes animais quando alimentados com uréia como principal suplemento protéico apresentam desempenho inferior aos animais que recebem suplementos protéicos contendo proteína verdadeira (farelo de soja). Paixão et al. (2004), avaliando o efeito da substituição da proteína da soja da dieta pelo nitrogênio não protéico da uréia sobre o desempenho de novilhos de origem leiteira em confinamento, verificaram que os animais que receberam como fonte protéica o farelo de soja, apresentaram melhores ganhos diários de peso, do que os animais que receberam uréia.

O farelo de soja é capaz de melhorar o rendimento de carcaça, fato que pode ser comprovado com o trabalho realizado por Sampaio et al. (1995), estes pesquisadores mostram que embora sem diferenças estatísticas, o ganho de peso de novilhos alimentados com rações com grão de soja $(1,14 \mathrm{~kg} / \mathrm{an} / \mathrm{dia})$ foi superior ao dos animais alimentados com farelo de soja $(0,94 \mathrm{~kg} / \mathrm{an} / \mathrm{dia})$, no entanto, não recomendam o uso do grão de soja, quando se objetiva melhores rendimentos de carcaça, pois observaram rendimentos de carcaça quente de $52,71 \%$ para os animais alimentados com grão de soja contra $55,99 \%$ para os do farelo de soja. 
TABELA 4. Composição Química da Casquinha de Soja e do Farelo de Soja

\begin{tabular}{|c|c|c|c|c|c|c|}
\hline Resíduo & $\begin{array}{l}\text { MS } \\
(\%)\end{array}$ & $\mathbf{P B}^{\mathbf{a}}$ & NDT $^{a}$ & FDNa $^{a}$ & FDA $^{a}$ & Lignina $^{a}$ \\
\hline $\begin{array}{l}\text { Casquinha de } \\
\text { Soja }\end{array}$ & 92,5 & 13,7 & - & 64,3 & 48,6 & 3,2 \\
\hline Farelo de Soja & 89,6 & 51,4 & 84,0 & 13,7 & 10,1 & - \\
\hline
\end{tabular}

a Valores expressos como \% da matéria seca. Adaptado de Paroliz et al. (2004)

\section{Resíduos Industriais de Mandioca}

Segundo dados da SEAB/DERAL (2001), a cultura de mandioca, no Paraná, vem assumindo importante destaque em relação aos demais estados brasileiros, tendo passado do oitavo lugar, nos últimos anos, para o terceiro lugar em maior área plantada, no ranking nacional. A produção mundial de mandioca é estimada em 160 milhões de toneladas, sendo o Brasil o segundo maior produtor (Leonel, 2001a).

A partir destes números observa-se, portanto, a grande quantidade de resíduos que são produzidos diariamente pelas indústrias da mandioca, que na sua maioria são voltadas para a produção de farinha e fécula.

Para Cereda (2001), na área do cultivo e processamento de mandioca, há muitos anos foi identificada uma forte demanda para transformação dos resíduos em subprodutos ou co-produtos, capazes de, ao mesmo tempo, reduzir impacto ambiental e gerar recursos. Marques \& Caldas Neto (2002) relatam que resíduos industriais da raiz de mandioca podem ser fontes alternativas de energia para ruminantes, assim como Jorge et al. (2002) afirmam que a mandioca e seus resíduos além de apresentarem potencial para serem utilizados na alimentação animal, apresentam também disponibilidade. 
Os resíduos da industrialização da mandioca são partes constituintes da própria planta, gerados em função do processo tecnológico adotado (Leonel, 2001b), se assemelham às raízes em termos de composição química (Tabela 5) por apresentarem elevados teores de carboidratos não estruturais (Caldas Neto et al., 2000). Tanto a qualidade quanto a quantidade dos resíduos variam bastante, em função de uma série de fatores tais como o cultivar, idade da planta, tempo após a colheita, tipo e regulagem do equipamento industrial, entre outros.

Existem vários resíduos da mandioca que podem ser utilizados para a alimentação de bovinos, entre eles encontram-se: casca de mandioca, raspa de mandioca, farinha de varredura e massa de fecularia. Entretanto, se faz importante ressaltar que regionalmente os subprodutos da mandioca recebem nomes diferentes o que dificulta a sua caracterização.

A casca de mandioca é um resíduo da indústria de farinha, resultante da prélimpeza da mandioca na indústria, constituído da ponta da raiz, casca e entre casca, é o principal resíduo da industrialização da mandioca para produção de farinha, representando $5,1 \%$ da raiz e apresenta uma umidade de $83,1 \%$ (Takahashi e Fagioto, 1990). A casca da mandioca apresenta altos teores de FDN e FDA e baixo teor de amido, por ser formada, principalmente por elementos estruturais.

A raspa de mandioca também resulta da pré-limpeza da mandioca, porém difere da casca devido ao equipamento utilizado. Raspa de mandioca, por ser a raiz de mandioca integral (casca e polpa), apresenta teores intermediários de FDN, FDA e amido. A casca de mandioca, assim como a raspa da mandioca devem ser secas ao sol antes de serem incorporadas às rações. Desta forma, as mesmas apresentam teores de matéria seca da ordem de $88 \%$. 
A farinha de varredura é o resíduo da indústria da mandioca formada pela farinha desclassificada para o consumo humano, fibra e resíduo resultante da limpeza da indústria (Marques et al., 2002). Desta forma, seu teor de MS é elevado (91,3\%). A farinha de varredura apresenta baixos teores em FDN e FDA e elevado teor em amido, isso ocorre em função desta ser constituída basicamente de polpa de raiz que é onde se concentra o maior teor de amido e menores teores de carboidratos estruturais.

A massa de fecularia ou como também é conhecida, bagaço ou farelo de mandioca, é um resíduo da indústria da fécula, proveniente da prensagem para extração da fécula ou amido da mandioca na indústria por via úmida, (Marques \& Caldas Neto, 2002; Bertol \& Lima, 1999), chegando a representar quantidade em peso igual ou maior que a quantidade de raízes processadas pela indústria (Cereda 2001). De acordo com Leonel (2001a), a massa de fecularia apresenta alta umidade $(85 \%)$ e pode ser caracterizada como material fibroso da raiz, contendo parte da fécula (amido) que não foi possível extrair no processamento. A utilização da massa de fecularia é dificultada devido ao seu elevado teor de umidade o que a torna bastante perecível, de difícil conservação e de transporte oneroso, limitando sua utilização a locais próximos as industrias. No entanto, a secagem deste subproduto é uma forma de permitir sua adequada conservação e transporte, otimizando sua utilização. O resíduo seco de fecularia, apesar de ter um custo mais elevado que o úmido devido aos custos envolvidos com a prensagem e secagem do material fresco, é de fácil utilização, permitindo seu uso em misturas concentradas. Este resíduo é utilizado para a alimentação de bovinos em confinamento, sendo um material rico em carboidratos de fácil e rápida fermentação ruminal (Caldas Neto et al., 2000), efetivo como fonte energética para a alimentação de bovinos em confinamento (Abrahão, 2004). Segundo Silveira (1995) a massa de fecularia pode ser aproveitada com resultados satisfatórios na engorda de bovinos. 
Ferreira et al. (1989), avaliando o desempenho de 100 animais da raça Nelore e mestiços das raças Holandesa x Zebu, usando farelo de algodão e cinco diferentes fontes de energia (milho, sorgo, raspa de mandioca, milho + sorgo$1: 1$ e milho + raspa de mandioca-1:1), concluíram que o GMD dos animais, alimentados com raspa de mandioca $(1,1 \mathrm{~kg})$ ou com raspa de mandioca + milho $(1,2 \mathrm{~kg})$, foram semelhantes aos obtidos com milho $(1,2 \mathrm{~kg})$ e milho + sorgo $(1,2 \mathrm{~kg})$ e superior ao GMD alcançado pelos animais que tinham como fonte energética o sorgo $(1,0 \mathrm{~kg})$. Marques et al. (2002) que compararam o milho com a casca da mandioca, a farinha de varredura e a raspa da mandioca na formulação de dietas para novilhas cruzadas e não observaram diferença entre as dietas avaliadas, com ganhos diários de $1,6 \mathrm{~kg}$ por animal. Os autores atribuíram o elevado ganho a um possível efeito compensatório já que as novilhas anteriormente ao experimento eram mantidas a pasto $e$ apresentavam ganhos de $0,4 \mathrm{~kg}$ ao dia, além de terem elevado potencial genético para ganho de peso. Da mesma forma, Maggioni et al. (2003) substituindo o milho pela massa de fecularia seca, também constataram que não houve interferência da substituição no GMD (1,06 kg/dia) destes animais. Lorenzoni \& Mella (1994), trabalhando com casca de mandioca, em substituição ao milho desintegrado com palha e sabugo e volumoso de baixa qualidade, em bovinos Nelore confinados, observaram GMD da ordem 0,7 kg, não diferindo do obtido com milho desintegrado com palha e sabugo.

No experimento de Marques (2002b) os valores para consumo de MS determinados para novilhas com peso médio inicial de aproximadamente 365 $\mathrm{kg}$, variaram de $11,7 \mathrm{~kg}$ para os animais que consumiram dieta com milho, $10,1 \mathrm{~kg}$ para a dieta com casca de mandioca, 9,5 $\mathrm{kg}$ para a dieta com raspa de mandioca e $8,5 \mathrm{~kg}$ para a dieta formulada com a farinha de varredura. Mostrando um nítido decréscimo no consumo de MS das dietas com resíduos de mandioca, que no caso da farinha de varredura foi atribuído pelo autor à baixa percentagem de extrato etéreo, a textura da farinha de varredura (pó) e tipo de saliva (com menos mucina), acredita-se que estes fatores aliados 
dificultam a deglutição, reduzindo assim o consumo. No entanto, Zeoula et al. (2000), não observaram a redução de ingestão de MS de ovinos, com o aumento dos níveis de farinha de varredura em substituição ao milho. Realizando a substituição do milho pela massa de fecularia seca, Maggioni et al. (2003), observaram valores para o consumo de matéria seca bastante próximos entre os tratamentos $(9,11$ e 9,04 kg/dia), respectivamente.

Lorenzoni \& Mella (1994) avaliaram a inclusão do resíduo da produção de farinha denominado "casquinha" em substituição ao milho desintegrado com palha e sabugo em rações para bovinos confinados, e concluíram que este resíduo poderia ser usado em até $45 \%$ do total da dieta. Zinn \& DePeters (1991) substituíram milho floculado à vapor por raspa de mandioca, na proporção de $0 \%, 15 \%$ e $30 \%$ da matéria seca total da ração, em bovinos mestiços confinados e concluíram que a raspa de mandioca pode participar em até $30 \%$ da ração, sem alterar o consumo de matéria seca.

Maggioni et al. (2003) não observaram diferença significativa no rendimento de carcaça quente quando avaliaram a substituição do milho pela massa de fecularia seca. Os animais que receberam dieta com milho apresentaram rendimento de $52,3 \%$, enquanto que os animais da dieta com milho + massa de fecularia apresentaram rendimento de carcaça de 51,1\%. Marques et al. (2002), comparando o milho com diferentes resíduos de mandioca (casca da mandioca, a farinha de varredura e a raspa da mandioca) na formulação de dietas para novilhas mestiças terminadas em confinamento, também observaram que o rendimento de carcaça (RC) não diferiu entre tratamentos $(50,9 \%)$, embora este valor tenha ficado abaixo do normal para essa categoria animal. Os autores alegaram que o baixo rendimento de carcaça poderia estar associado à não observância de jejum de 12:00 horas de sólidos antes do abate e ao processo de limpeza ou toalete das carcaças que foram realizadas pelos frigoríficos, em razão de maior ou menor rigidez no processo de limpeza da carcaça. 
Quando Macedo et al. (2004) substituíram o milho pela massa de fecularia úmida, observaram que tal substituição não afeta o perfil de ácidos graxos ou as relações de ácidos graxos poliinsaturados / ácidos graxos saturados da carcaça.

Caldas Neto et al. (2000), avaliando o efeito de fontes energéticas: milho, raspa de mandioca, farinha de varredura e casca de mandioca sobre $\mathrm{o} \mathrm{pH}$, concentração de N-Nh3 e eficiência microbiana no rúmen, constataram que não houve influência da fonte de energia sobre o pH do líquido ruminal, e que a ração contendo farinha de varredura proporcionou menor concentração de amônia e maior eficiência microbiana aparente. Através destes resultados os autores concluíram que existe uma melhor sincronização da disponibilidade de energia e nitrogênio no rúmen para a ração com farinha de varredura, que é uma fonte de amido com alta degradabilidade e digestibilidade ruminal. Lorenzoni \& Mella (1994) realizaram a inclusão de casca de mandioca em substituição ao milho desintegrado com palha e sabugo em rações para bovinos confinados, e observaram que o coeficiente de digestibilidade aparente da matéria seca da ração total melhorou com o aumento dos níveis de casca e a melhora chegou a doze pontos percentuais quando se substitui totalmente 0 milho pela casca de mandioca.

TABELA 5. Composição Química de Resíduos de Mandioca.

\begin{tabular}{l|ccccc}
\hline Resíduo & $\begin{array}{c}\text { MS } \\
(\%)\end{array}$ & PB $^{\mathbf{a}}$ & Amido $^{\mathbf{a}}$ & FDN $^{\mathbf{a}}$ & FDA $^{\mathbf{a}}$ \\
& $\mathbf{( \% )}$ & & & & \\
\hline Casca de Mandioca & 89,2 & 3,7 & 48,0 & 28,6 & 20,4 \\
Raspa de Mandioca & 88,7 & 3,6 & 82,5 & 8,5 & 5,7 \\
Farinha de Varredura & 91,3 & 1,2 & 84,8 & 7,3 & 5,5 \\
Massa de Fecularia & 89,0 & 1,9 & 75,0 & 30,5 & 22,6 \\
\hline
\end{tabular}

a Valores expressos como \% da matéria seca.

Adaptado de Marques et al. (2002); Maggioni et al. (2003). 


\section{Resíduos de Destilaria de Álcool}

A necessidade do aumento da produtividade dos animais ruminantes tem acarretado a busca por incrementos na capacidade dos animais em utilizarem o alimento consumido, tanto por melhorias na capacidade de digestão quanto por aumento na eficiência metabólica do hospedeiro e da microbiota ruminal. Contudo, a melhoria destes parâmetros, na eficiência da utilização das rações também pode ser obtida através de aditivos que alterem determinados processos metabólicos ou condições fermentativas e absortivas ao longo do trato digestório dos animais.

Há muito tempo existe interesse na manipulação da fermentação ruminal para a melhoria da eficiência produtiva dos ruminantes domésticos, principalmente dos bovinos. Essa manipulação foi iniciada com o uso de antimicrobianos ionóforos, (os quais atualmente já são amplamente utilizados) e teve continuidade com outros promotores de crescimento, principalmente os probióticos, que são produtos baseados em culturas de organismos vivos nãopatogênicos que se estabelecem no trato digestório podendo levar a alterações na população microbiana normalmente presente neste trato, o que resultaria em maior digestão e proteção contra disfunções ou doenças. Provavelmente nos próximos anos, o uso de ionóforos deverá ser proibido, devido suspeita de causar resistência bacteriana no ser humano. No entanto, outros aditivos como o composto de levedura, apresentam um ótimo potencial, podendo funcionar como uma nova opção aos ionóforos, por serem produtos naturais, provavelmente melhorando a conversão alimentar e aumentando a lucratividade.

Este fato é de grande importância para o Brasil, tendo em vista o potencial de produção de levedura (Saccharomyces sp.), pelas destilarias de álcool. A levedura de cana (Saccharomyces cerevisiae), possui alto valor protéico e bom balanço de aminoácidos. As leveduras são fungos unicelulares, especialmente 
do gênero Saccharomyces, e são tradicionalmente utilizados na fermentação do açúcar de alimentos para o consumo humano. O uso em alimentação de bovinos de corte foi ligado ao aumento na digestibilidade da matéria seca, especialmente da fibra, melhorando a eficiência alimentar e ganho de peso. È muito palatável. Existe variação na eficiência das diferentes cepas de Saccharomyces cerevisae em promover melhoria no desempenho dos bovinos (Newbond et al 1996). Existem indicações de que aditivos microbianos, como a levedura, podem melhorar a produção de ruminantes em cerca de $7 \%$ a $8 \%$, magnitude semelhante à de ionóforos (Wallace, 1994)

Dawson et al. (1990) ressaltaram que o aumento no número de bactérias do rúmen (especialmente bactérias celulolíticas) é o efeito mais comum da suplementação com leveduras, e que alguns tipos de bactérias apresentam melhor desempenho na presença destas, e alguns fatores relacionados com essas respostas são: fornecimento de fatores de crescimento - vitaminas, ácidos dicarboxílicos (fumarato, malato), remoção de oxigênio por Saccharomyces, efeito tampão $(\mathrm{pH}>6)$ e redução do número de protozoários. Iwanska et al. (1999) sugerem ser necessário um período de cerca de duas semanas para que a microflora se adapte ao aporte de levedura e a fermentação ruminal seja estabilizada. Justus Neto et al. (2003) avaliando o ganho de peso de novilhos em crescimento com o uso de levedura, observaram que o ganho médio diário (GMD) apresentou um aumento progressivo no período de 84 dias, demonstrando que nesta categoria animal há influência do tempo de confinamento, sendo que o maior ganho de peso $(1,34 \mathrm{~kg} / \mathrm{dia})$ ocorreu na fase final, a partir dos 56 dias.

Zeoula et al. (2004) avaliando o efeito de aditivos vs níveis de concentrado na ração, observaram que a digestibilidade in vitro da matéria seca (DIVMS) das rações com níveis de concentrado variando de $0 \%$ a $50 \%$ foram superiores com a adição de levedura em relação à adição de monensina. 
De acordo com Wallace (1994), a ação do Saccharomyces, parece se concentrar na elevação do consumo de matéria seca, provocada por elevação na taxa de degradação da fibra, especialmente em dietas ricas em concentrado, e no fluxo de nitrogênio absorvível. Resultados positivos da inclusão de levedura sobre o consumo de matéria seca foram relatados por Adams et al. (1995), que comprovam que o efeito das leveduras pode ser maior em dietas com maior teor de concentrados. Com o uso da levedura na alimentação dos ruminantes, há um aumento expressivo no número de bactérias celulolíticas e as que utilizam lactato. Ocorre também maior estabilidade do ambiente ruminal, principalmente quando se utiliza dietas com altos teores de amido, reduzindo as variações diurnas de pH, amônia

No rúmen o Saccharomyces secreta compostos químicos que além de servirem como fatores de crescimento para as bactérias do rúmen, contribuem para a nutrição do bovino. Na avaliação de características de carcaça e de carne de bovinos de corte recebendo dois tipos de suplementos, Pádua et al. (2003), observaram que os animais que receberam suplemento com aditivo (levedura) apresentaram melhor peso para o traseiro da carcaça em relação aos animais que receberam suplemento sem aditivo. Isto pode ser explicado devido ao fato dos animais que receberam suplemento com aditivo terem apresentado maiores ganhos de peso diário $(0,667 \mathrm{~kg} / \mathrm{dia})$ que os animais que receberam suplemento sem aditivo ( $0,633 \mathrm{~kg} / \mathrm{dia})$, fato que propiciou conseqüentemente, maiores pesos de carcaça.

$\mathrm{O}$ pH para crescimento ótimo de Saccharomyces é cerca de 4,5. Devido ao pH normal do rúmen (próximo de 6,5 ) a taxa de crescimento deste fungo é menor, dessa forma as leveduras devem ser suplementadas continuamente. 


\section{Conclusões}

A utilização de fontes alternativas de nutrientes, de baixo preço, pode colaborar na diminuição do custo de produção da carne bovina. Além do aspecto de agressão ambiental que os resíduos agroindustriais apresentam, o não aproveitamento dos mesmos constitui desperdício, uma vez que os resíduos podem ser fontes nutritivas para os ruminantes, pois são capazes de substituir componentes normalmente utilizados em rações, sem comprometer o desempenho dos animais que a estarão consumindo. Além de apresentarem custos reduzidos principalmente para as produções que se encontram próximas das indústrias.

Porém, existem algumas limitações que podem fazer com que os resíduos tenham uma utilização mais restrita, entre elas a quantidade de água, que acabam acarretando problemas de transporte, representado pelo alto custo da coleta, a conservação de seus resíduos e a necessidade, em alguns casos, de processos de tratamento para melhoria de seu valor nutritivo.

Há muitas possibilidades de uso dos diferentes resíduos gerados pelas agroindústrias e não se pode dizer que exista uma solução única, e sim usos potenciais de acordo com a situação de mercado e da indústria. Todavia, devese levar em consideração o preço do produto, o custo do transporte, já que muitas vezes o valor nutricional destes resíduos não são muito elevados.

\section{LITERATURA CITADA}

ABRAHÃO, J.J.S. Diferentes subprodutos da mandioca na alimentação de bovinos visando a produção de carne e leite. Maringá: UEM, Curso de Zootecnia, 2000. (Dados não Publicados).

ABRAHÃO, J.J.S. Resíduos da extração da fécula de mandioca em substituição ao milho: desempenho animal, digestibilidade, características da carcaça e da carne de tourinhos e novilhas terminados em confinamento. Maringá - Pr: Universidade Estadual de Maringá, 2004. 128p. Tese (Doutorado em Zootecnia) Universidade Estadual de Maringá, 2004. 
Maggioni, D. e Marques, J.A. Resíduos agroindustriais na alimentação de ruminantes: uma revisão. PUBVET, Londrina, V. 1, N. 6, Art\#66, Nov2, 2007.

ADAMS, A.L.; HARRIS, B. JR.; VAN HORN, H.H.; et al. Effects of varying forage types on milk production responses to whole cottonseed, tallow, and yeast. Journal Dairy Science, v.78, n.3, p.573-581, 1995.

ANDERSON, S.J., MERRILL, J.K., MCDONNELL, M.L., et al. Digestibility and utilization of mechanically processed soybean hulls by lambs and steers. Journal Animal Science. v.66, n.11, p.2965-2976, 1988.

ASHBELL, G. Conservation of citrus peel ensiling for ruminat feed. In: SIMPÓSIO UTILIZAÇÃO DE SUBPRODUTOS AGROINDUSTRIAIS E RESÍDUOS DE COLHEITA NA ALIMENTAÇÃO DE RUMINANTES. São Carlos, SP. Anais... EMBRAPA/UEPAE de São Carlos, SP., 1992.

ASHBELL, G.; WEINBERG, Z.G. Orange peels: the effect of blanching and calcium hidroxide addtition on ensiling losses. Biol. Wastes., v.23, p.73-77, 1988.

ASSIS, A.J.; CAMPOS, J.M.S; TEIXEIRA, R.M.A.; et al. Casca de Algodão em Dietas de Vacas Leiteiras. I - Consumo, Variação de Peso, Produção e Composição do Leite. In: REUNIÃO ANUAL DA SOCIEDADE BRASILEIRA DE ZOOTECNIA, 41, 2004, Campo Grande. Anais... Campo Grande: Sociedade Brasileira de Zootecnia, 2004.

BERGAMASCHINE, A.F.; ISEPON, O.J.; CASSIOLATO, M.R.; et al. Qualidade e Degradação "In Situ" de Silagens de Polpa de Citrus. In: REUNIÃO ANUAL DA SOCIEDADE BRASILEIRA DE ZOOTECNIA, 35, 1998, Botucatu. Anais... Botucatu, Sociedade Brasileira de Zootecnia, 1998.

BERTOL, T. M. \& LIMA, G.J.M.M. Níveis de Resíduo Industrial de Fécula da Mandioca na Alimentação de Suínos em Crescimento e Terminação. Pesquisa Agropecuária Brasileira, v.34, n.2, p.243-248, 1999.

BRANCO, A.F.; ZEOULA, L.M.; PRADO, I.N.; et al. Valor Nutritivo da Polpa de Citrus In Natura para Ruminantes. Revista Unimar, v.16 (suplemento 1), p.37-48, 1994.

BRUNO FILHO, J.R.; BERCHIELLI, T.T.; ANDRADE, P.; et al. Digestibilidade da Polpa Cítrica Peletizada na Alimentação de Bovinos. In: REUNIẪO ANUAL DA SOCIEDADE BRASILEIRA DE ZOOTECNIA, 37, 2000, Viçosa. Anais... Viçosa: Sociedade Brasileira de Zootecnia, 2000.

CALDAS NETO, S.F.; ZEOULA, L.M.; BRANCO, A.F.; et al. Mandioca e Resíduos das Farinheiras na Alimentação de Ruminantes: pH, Concentração de Amônia e Eficiência Microbiana. In: REUNIÃO ANUAL DA SOCIEDADE BRASILEIRA DE ZOOTECNIA, 37, 2000, Viçosa. Anais... Viçosa: Sociedade Brasileira de Zootecnia, 2000.

CARVALHO, M.P. Citrus. In: ANAIS DO VI SIMPÓSIO SOBRE NUTRIÇÃO DE BOVINOS, 6a, 1995, Piracicaba. Anais ... Piracicaba, 1995, p.171-214.

CEREDA, M.P. Caracterização dos Subprodutos da Industrialização da Mandioca. In: CEREDA, M.P. Manejo, Uso e Tratamento de Subprodutos da Industrialização da Mandioca. Vol.4, Fundação Cargill, São Paulo, 2001, p.13-37

CHASE,C.C., HIBBERD, C.A. Utilization of low-quality native grass hay by beef cows fed increasing quantities of corn grain. Journal Animal Science. v.65, n.2, p.557-565, 1987.

CHIZZOTTI, M.L.; VALADARES FILHO, S.C.; LEÃO, M.I.; et al. Consumo e Digestibilidade em Novilhos Alimentados com Diferentes Níveis de Casca de Algodão em Substituição Parcial à Silagem de Capim-Elefante. In: REUNIÃO ANUAL DA SOCIEDADE BRASILEIRA DE ZOOTECNIA, 40, 2003, Santa Maria. Anais... Santa Maria: Sociedade Brasileira de Zootecnia, 2003.

DAWSON, K.A.; NEWMAN, K.E.; BOLING, J.A. Effects of microbial supplements containing yeast and lactobacilli on rouguage-fed ruminal microbial activities. Jounal Animal Science, v.68, n.10, p.3392-3398, 1990.

FATURI, C.; EZEQUIEL, J.M.B.; STIAQUE, M.G. et al. Livre escolha de dietas contendo polpa cítrica mais protenose ou polpa cítrica mais uréia por novilhos de corte. In: REUNIÃO ANUAL DA SOCIEDADE BRASILEIRA DE ZOOTECNIA, 41, 2004, Campo Grande. Anais... Campo Grande: Sociedade Brasileira de Zootecnia, 2004.

FERREIRA, A.C.H.; NEIVA, J.N.M; RODRIGUEZ, N.M. et al. Valor Nutritivo de Silagens de Capim Elefante com Níveis Crescentes de Subprodutos da Indústria do Suco do Abacaxi. 
Maggioni, D. e Marques, J.A. Resíduos agroindustriais na alimentação de ruminantes: uma revisão. PUBVET, Londrina, V. 1, N. 6, Art\#66, Nov2, 2007.

In: REUNIÃO ANUAL DA SOCIEDADE BRASILEIRA DE ZOOTECNIA, 41, 2004, Campo Grande. Anais... Campo Grande: Sociedade Brasileira de Zootecnia, 2004.

FERREIRA, J. J.; MARQUES J. N.; MIRANDA, C. S. Efeito do milho, sorgo e raspa de mandioca na ração sobre o desempenho de novilho confinados. Revista Brasileira de Zootecnia, v.18, n.4, p.306-313, 1989.

FIGUEIRÓ, I. Alugar pasto começa a ficar inviável. Revista DBO, n.284, junho, 2004.

FONTES, N.A.; EZEQUIEL, J.M.B; FATURI, C. et al. Efeito de Dietas Contendo Milho e Polpa Cítrica Associados ao Farelo de Girassol ou Uréia sobre o Desempenho de Novilho Confinados. In: REUNIÃO ANUAL DA SOCIEDADE BRASILEIRA DE ZOOTECNIA, 41, 2004, Campo Grande. Anais... Campo Grande: Sociedade Brasileira de Zootecnia, 2004.

GASTALDI, K.A.; CARMO, F.R.G.; NOGUEIRA, K.A.; et al. Efeito de Fontes de Nitrogênio, Relações Volumoso : Concentrado e Adição de Casca de Soja no Desempenho de Novilhos Nelore Confinados. In: REUNIÃO ANUAL DA SOCIEDADE BRASILEIRA DE ZOOTECNIA, 37, 2000, Viçosa. Anais... Viçosa: Sociedade Brasileira de Zootecnia, 2000.

GOMES, I.P.O., ANDRADE, P. Níveis de substituição de milho por casca d grão de soja na dieta de bovinos. I. Desempenho em confinamento. In: REUNIÃO ANUAL DA SBZ, 33, 1996, Fortaleza. Anais... Fortaleza, Sociedade Brasileira de Zootecnia, 1996.

GRIGSBY, K.N., KERLEY, M.S., PATERSON, J.A., et al. Combinations of starch and digestible fiber in supplements for steers consuming a low-quality bromegrass hay diet. Journal Animal Science. v.71, n.4, p.1057-1064, 1993.

HENRIQUE, W.; LEME, P.R.; LANNA, D.P.D.; et al. Efeito de Diferentes Fontes de Polpa Cítrica Peletizada e Níveis de Concentrado na Dieta de Novilhas Confinadas. In: REUNIÃO ANUAL DA SOCIEDADE BRASILEIRA DE ZOOTECNIA, 35, 1998, Botucatu. Anais... Botucatu, Sociedade Brasileira de Zootecnia, 1998.

ÍTAVO, L.C.V; SANTOS, G.T.; JOBIM, C.C.; et al. Consumo e Parâmetros de Fermentação Ruminal de Vacas Fistuladas Alimentadas com Silagem de Bagaço de Laranja em Níveis de Substituição à Silagem de Milho. In: REUNIÃO ANUAL DA SOCIEDADE BRASILEIRA DE ZOOTECNIA, 36, 1999, Porto Alegre. Anais... Porto Alegre: Sociedade Brasileira de Zootecnia, 1999.

IWANSKA, S.; STRUSINSKA, D. ZALEWSKI, W.; et al. The effect of Saccharomyces cerevisae 1026 used alone or with vitamin-mineral premix on milk yield and milk composition in dairy cows. Acta Veterinaria Hungarica, v.47, n.1, p.41-52, 1999.

JORGE, J.R.V.; ZEOULA, L.M.; PRADO, I.N.; et al. Substituição do Milho pela Farinha de Varredura (Manihot esculenta, Crantz) na Ração de Bezerros Holandeses. 2. Digestibilidade e Valor Energético. Revista Brasileira de Zootecnia, v.31, n.1, p.205-212, 2002.

JUSTUS NETO, C.; VALENTIN, A.D.; ROSSI JR, P. Ganho de Peso com Probiótico, Ionóforo e Complexo Mineral Orgânico na Dieta de Novilhos em Recria Alimentados com Resíduos Agro-Industriais. In: REUNIÃO ANUAL DA SOCIEDADE BRASILEIRA DE ZOOTECNIA, 40, 2003, Santa Maria. Anais... Santa Maria: Sociedade Brasileira de Zootecnia, 2003.

LALLO, F.H.; PRADO, I.N.; NASCIMENTO, W.G.; et al. Níveis de Substituição da Silagem de Milho pela Silagem de Resíduos Industriais de Abacaxi sobre a Degradabilidade Ruminal em Bovinos de Corte. Revista Brasileira de Zootecnia, v.32, n.3, p.719-726, 2003.

LALLO, F.H.; PRADO, I.N.; ZEOULA, L.M.; et al. Substituição da Silagem de Milho pela Silagem de Resíduos Industriais de Abacaxi sobre a Digestibilidade Aparente de Rações em Bovinos Confinados. In: REUNIÃO ANUAL DA SOCIEDADE BRASILEIRA DE ZOOTECNIA, 39, 2002, Recife. Anais... Recife: Sociedade Brasileira de Zootecnia, 2002.

LEONEL, M. O Farelo, Subproduto da Extração de Fécula de Mandioca. In: CEREDA, M.P. Manejo, Uso e Tratamento de Subprodutos da Industrialização da Mandioca. Vol.4, Fundação Cargill, São Paulo, 2001a, p.211-216.

LEONEL, M. Uso dos Subprodutos da Industrialização da Mandioca na Alimentação Animal. In: CEREDA, M.P. Manejo, Uso e Tratamento de Subprodutos da Industrialização da Mandioca: Vol.4, Fundação Cargill, São Paulo, 2001b. p.229-239.

LORENZONI, W.R. \& MELLA, S.C. Avaliação de resíduo obtido de lavagem de raiz de mandioca como alimento energético para bovinos. In: CEREDA, M.P. Resíduos da Industrialização da Mandioca: Paulicéia, São Paulo, 1994. p.91-100. 
Maggioni, D. e Marques, J.A. Resíduos agroindustriais na alimentação de ruminantes: uma revisão. PUBVET, Londrina, V. 1, N. 6, Art\#66, Nov2, 2007.

MACEDO, L.M.A.; PRADO, I.N.; ABRAHÃO, J.J.S.; et al. Perfil dos Ácidos Graxos e Relações Ácidos Graxos Poliinsaturados/ Ácidos Graxos Saturados e Omega 6 e 3 do Músculo Longissimus Dorsi de Tourinhos Terminados em Confinamento. In: REUNIÃO ANUAL DA SOCIEDADE BRASILEIRA DE ZOOTECNIA, 41, 2004, Campo Grande. Anais... Campo Grande: Sociedade Brasileira de Zootecnia, 2004.

MAGGIONI, D. MARQUES, J. de A.; LUGÃO, S.M.B.; et al. Evaluation of Dry Cassava Residue of Extraction Amide in Replacement of Corno $\mathrm{n}$ Performance for Feedlot Heifers. In: WORLD CONFERENCE ON ANIMAL PRODUCTION, 9, 2003, Porto Alegre. Anais... Porto Alegre, 2003.

MARQUES, J. de A. \& CALDAS NETO, S.F. Mandioca na alimentação animal: Parte aérea e Raiz. Campo Mourão - PR, CIES, 2002. 28p.

MARQUES, J. de A.; PRADO, I. N.; ZEOULA, L. M. et al. Avaliação da mandioca e seus resíduos industriais em substituição ao milho no desempenho de novilhas confinadas. Revista Iniciare, v.1, n.3, p.37-43. 2002.

McCULLOUGH, M.E. Silage and silage fermentation. Feedstuffs, p.49-52, 1977.

MOLETTA, J.L. Utilização da Soja Grão ou do Caroço de Algodão, na Terminação de Bovinos de Corte em Confinamento. In: REUNIÃO ANUAL DA SOCIEDADE BRASILEIRA DE ZOOTECNIA, 36, 1999, Porto Alegre. Anais... Porto Alegre: Sociedade Brasileira de Zootecnia, 1999.

MONTEIRO, A.L.G.; GARCIA, C.A.; NERES, M.A.; et al. Efeito da Substituição do Milho pela Polpa Cítrica no Desempenho e Características das Carcaças de Cordeiros Confinados. In: REUNIÃO ANUAL DA SOCIEDADE BRASILEIRA DE ZOOTECNIA, 35, 1998, Botucatu. Anais... Botucatu, Sociedade Brasileira de Zootecnia, 1998.

MOREIRA, P.S.; REIS, R.B.; LANA, A.M.Q.; et al. Produção e Composição do Leite de Vacas Alimentadas com Polpa Cítrica em Substituição ao Milho. In: REUNIÃO ANUAL DA SOCIEDADE BRASILEIRA DE ZOOTECNIA, 41, 2004, Campo Grande. Anais... Campo Grande: Sociedade Brasileira de Zootecnia, 2004.

MULLER, Z.O. Feeding potential of pineapple Wastw for cattle. World Animal Review, v.25, n.1, p.25-28, 1978.

NEWBOLD, C.J.; WALLACE, R.J.; McINTOSH, F.M. Mode of action of the yeast Saccharomyces cerevisae as a feed additive for ruminants. British Jounal of Nutrition, v.76, n.2, p.249261, 1996.

NRC. Nutrient requirements of beef cattle. 6th ed., Washington, DC: National Academy Press, 1996. 242p.

ORSKOV, E.R. The feeding of ruminants: principles and practice. Rowett Research Institute, Chalcombe Publications, 1987.

PÁDUA, J.T.; MIYAGI, E.S.; PRADO, C.S.; et al. Características de Carcaça e da Carne de Bovinos de Corte Compostos, Cruzados e Puros, Mantidos a Pasto, Utilizando Dois Tipos de Suplementação. In: REUNIÃO ANUAL DA SOCIEDADE BRASILEIRA DE ZOOTECNIA, 40, 2003, Santa Maria. Anais... Santa Maria: Sociedade Brasileira de Zootecnia, 2003.

PAIXÃO, M.L.; LEÃO, M.I.; VALADARES FILHO, S.C.; et al. Efeito de Níveis de Concentrado e de Uréia em Rações para Novilhos Holandeses Confinados. In: REUNIÃO ANUAL DA SOCIEDADE BRASILEIRA DE ZOOTECNIA, 41, 2004, Campo Grande. Anais... Campo Grande: Sociedade Brasileira de Zootecnia, 2004.

PAROLIZ, A.F.P.; BRANCO, A.F.; NEVES, C.A.; et al. Digestibilidade In Vitro da Casquinha de Soja, Resíduo de Soja e Casca de Algodão. In: REUNIÃO ANUAL DA SOCIEDADE BRASILEIRA DE ZOOTECNIA, 41, 2004, Campo Grande. Anais... Campo Grande: Sociedade Brasileira de Zootecnia, 2004.

PINHEIRO, A.D.; PRADO, I.N.; ALCALDE, C.R.; et al. Efeito dos Níveis de Substituição do Milho pela Polpa de Citrus Peletizada sobre a Digestibilidade Aparente em Bovinos Mestiços Confinados. Acta Scientiarum, v.22, n.3, p.793-799, 2000.

PRADO, I.N.; LALLO, F.H.; ZEOULA, L.M.; et al. Níveis de Substituição da Silagem de Milho pela Silagem de Resíduos Industriais de Abacaxi sobre o Desempenho de Bovinos Confinados. Revista Brasileira de Zootecnia, v.32, n.3, p.737-744, 2003.

PRADO, I.N. \& MOREIRA, F.B. Suplementação de Bovinos no Pasto e Alimentos Alternativos Usados na Bovinocultura. Maringá - PR. EDUEM - UEM, 2002. 162p. 
Maggioni, D. e Marques, J.A. Resíduos agroindustriais na alimentação de ruminantes: uma revisão. PUBVET, Londrina, V. 1, N. 6, Art\#66, Nov2, 2007.

RODRIGUES, R.C.; PEIXOTO, R.R. Avaliação de Alimentos. Composição Bromatológica, Digestibilidade e Balanço de Nitrogênio de Resíduo de Indústria de Abacaxi. In: REUNIÃO ANUAL DA SOCIEDADE BRASILEIRA DE ZOOTECNIA, 27, 1990, Campinas. Anais... Campinas: Sociedade Brasileira de Zootecnia, 1990a.

RODRIGUES, R.C.; PEIXOTO, R.R. Avaliação de Alimentos. Composição Bromatológica, Digestibilidade e Balanço de Nitrogênio de Resíduo de Indústria de Abacaxi Ensilado. In: REUNIÃO ANUAL DA SOCIEDADE BRASILEIRA DE ZOOTECNIA, 27, 1990, Campinas. Anais... Campinas: Sociedade Brasileira de Zootecnia, 1990b.

SAMPAIO, A.A.M., OLIVEIRA, M.D.S., TOSI, H. \& GAVA FILHO, J.C. Utilização de soja-grão e do farelo de soja, na terminação de bovinos castrados e inteiros em confinamento. In: REUNIÃO ANUAL DA SOCIEDADE BRASILEIRA DE ZOOTECNIA, 32, 1995, Brasília. Anais... Brasília: Sociedade Brasileira de Zootecnia, 1995.

SEAB/DERAL. Acompanhamento da Situação Agropecuária no Paraná. 2001, p.99

SILVEIRA, J.A. da. Tem resíduos virando carne. A Granja, v.51, n.562, p.41-42, 1995.

SIQUEIRA, G.B.; ALCALDE, C.R.; BERTIPAGLIA, L.M.A; et al. Utilização de Resíduo de Maracujá e Silagens de Híbridos de Milho, na Terminação de Bovinos de Corte em Confinamento. Acta Scientiarum, v.21, n.3, p.749-753, 1999.

SURITA, C.A.S.; JOBIM, C.C.; PINTO, A.A.; et al. Avaliação de Fontes Protéicas na Composição do Bagaço de Laranja Ensilado. In: REUNIÃO ANUAL DA SOCIEDADE BRASILEIRA DE ZOOTECNIA, 35, 1998, Botucatu. Anais... Botucatu, Sociedade Brasileira de Zootecnia, 1998.

TAKAHASHI, M. e FAGIOTO, R. Balanço em Massa de Industria de Farinha de Mandioca em Paranavaí. In: CONGRESSO BRASILEIRO DE MANDIOCA, Londrina, 4, 1990. Anais... Londrina, 1990.

THIAGO, R.L.R. de S.; SILVA, J.M.; FEIJÓ, G.L.D.; et al. Substituição do Milho pelo Sorgo ou Casca de Soja em Dietas para a Engorda de Bovinos em Confinamento. In: REUNIÃO ANUAL DA SOCIEDADE BRASILEIRA DE ZOOTECNIA, 37, 2000, Viçosa. Anais... Viçosa: Sociedade Brasileira de Zootecnia, 2000.

VAN SOEST, P. J. Nutritional ecology of the ruminant. 2.ed. Ithaca: Cornell Univ. Press, 1994. $476 \mathrm{p}$.

VELLOSO, L. Uso da polpa cítrica na alimentação animal. Comunicado Científico FMVZ USP, v.9, n.2,p.163-180, 1985.

VILELLA, S.D.J., VALADARES FILHO, S. de C., DA SILVA, J.F.C, LEÃO,M.I., CECON, P.R. \& PEREIRA, J.C. Efeito da inclusão do caroço de algodão na dieta de vacas em lactação sobre o consumo, taxa de passagem, $\mathrm{pH}$ e concentração de amônia no rúmen. In: REUNIÃO DA SOCIEDADE BRASILEIRA DE ZOOTECNIA, 32, 1995, Brasília. Anais... Brasília: Sociedade Brasileira de Zootecnia, 1995.

WALLACE, R.J. Ruminal microbiology, biotechnology, and ruminant nutrition: progress and problems. Journal Animal Science, Champaign, v.72, n.11, p.2992-3003, 1994.

ZEOULA, L.M.; BELEZE, J.R.F.; GERON, L.J.V. et al. Aditivos vs Nível de Concentrado na Ração: Digestibilidade "In Vitro" da Matéria Seca. In: REUNIÃO ANUAL DA SOCIEDADE BRASILEIRA DE ZOOTECNIA, 41, 2004, Campo Grande. Anais... Campo Grande: Sociedade Brasileira de Zootecnia, 2004.

ZEOULA, L.M; PRADO, I.N.; CALDAS NETO, S.F.; et al. Substituição do Milho pela Farinha de Varredura sobre o Consumo Voluntário e Digestibilidade em Ovinos. In: REUNIÃO ANUAL DA SOCIEDADE BRASILEIRA DE ZOOTECNIA, 37, 2000, Viçosa. Anais... Viçosa: Sociedade Brasileira de Zootecnia, 2000.

ZINN, R.A. \& DePETERS, E.J. Comparative Feeding of Tapioca Pellets for Feedlot Cattle. Journal Animal Science, v.69, p.4726-4733, 1991. 
Maggioni, D. e Marques, J.A. Resíduos agroindustriais na alimentação de ruminantes: uma revisão. PUBVET, Londrina, V. 1, N. 6, Art\#66, Nov2, 2007. 